\title{
Highly elastic wrinkled structures for stable and low volume-expansion lithium-metal anodes
}

\author{
Wenwen $\mathrm{Lu}^{1,2}$, Huicong Yang ${ }^{1,2}$, Jing Chen ${ }^{1}$, Chihang $\operatorname{Sun}^{1}$ and Feng $\mathrm{Li}^{1,2^{*}}$
}

\begin{abstract}
Lithium ( $\mathrm{Li}$ ) metal is promising for high energy density batteries due to its low electrochemical redox potential and high specific capacity. However, the formation of dendrites and its tendency for large volume expansion during plating/stripping restrict the application of $\mathrm{Li}$ metal in practical scenarios. In this work, we developed reduced graphene oxide-graphitic carbon nitride ( $\mathrm{rGO}-\mathrm{C}_{3} \mathrm{~N}_{4}, \mathrm{GCN}$ ) with highly elastic and wrinkled structure as the current collector. Lithiophilic site $\mathrm{C}_{3} \mathrm{~N}_{4}$ in $\mathrm{GCN}$ could reduce the nucleation overpotential. In addition, this material effectively inhibited electrode expansion during cycling. At the same time, due to its high elasticity, GCN could release the stress induced by $\mathrm{Li}$ deposition to maintain structural integrity of the electrode. Limetal anodes with GCN exhibited small volume expansion, high Coulombic efficiency (CE) of $\mathbf{9 8 . 6 \%}$ within 300 cycles and long cycling life of more than $\mathbf{1 7 0 0} \mathrm{h}$. This work described and demonstrated a new approach to construct flexible current collectors for stable lithium-metal anodes.
\end{abstract}

Keywords: lithium-metal anode, 3D current collector, high elasticity

\section{INTRODUCTION}

In recent years, there have been rapid developments in electric vehicles and portable electronic products, but lithium-ion batteries (LIBs) can hardly meet the high energy densities required in future applications. Therefore, new battery systems with high energy densities are needed $[1,2]$. Lithium metal $(\mathrm{Li})$ is regarded as the nextgeneration anode material due to its high energy density (3860 $\mathrm{mA} \mathrm{h} \mathrm{g}^{-1}$ ) and low electrochemical redox potential $(-3.04 \mathrm{~V}$ vs. standard hydrogen electrode) [3-5]. However, the dendrite formation and volume expansion of $\mathrm{Li}$ restrict its potential application [6,7]. Firstly, uncontrolled growth of $\mathrm{Li}$ dendrites leads to the formation of non-active $\mathrm{Li}$, which causes irreversible capacity loss and low Coulombic efficiency (CE). Furthermore, dendrites can pierce the separator, which can cause shortcircuit and lead to safety issues [8-10]. Unlike the electrode materials in LIBs that undergo intercalation, the plating/stripping of $\mathrm{Li}$ is a phase-conversion reaction, which results in infinite volume expansion in the electrodes. This leads to their fragmentation and pulverization and deteriorates their cycling performance [11-13].

Therefore, several strategies were developed to resolve these issues [14-17], which can be classified as follows: construct artificial solid electrolyte interphase (SEI) [18], optimize electrolyte [19], and use three-dimensional (3D) current collectors [20,21]. A 3D current collector, when used as the substrate for Li deposition, has great impact on Li nucleation and growth processes. The porous structure with abundant active sites of $3 \mathrm{D}$ current collector can facilitate Li-ion flux and nucleation, reduce the local current density, and inhibit Li dendrites. These structures have high application prospects in Li-metal batteries [22]. The main strategies to optimize 3D current collectors are as follows: (1) design the pore structure to facilitate Li-ion migration $[23,24]$ and (2) modify the lithiophilic sites to reduce Li nucleation overpotential and promote uniform electrodeposition $[25,26]$. However, the incorporation of non-active frameworks in the electrodes decreases the intrinsic capacity advantages of Li metal. To ensure high volumetric/gravimetric energy density of Limetal anodes, the constructed 3D current collectors should have small volume and low weight. Because carbon nanomaterials have the advantages of low weight, high pore volume, and high electrical conductivity, they are promising candidates for $3 \mathrm{D}$ current collectors. Such porous structures with no tensile strength can accommodate only limited amount of Li. They fail at high

\footnotetext{
${ }^{1}$ Shenyang National Laboratory for Materials Science, Institute of Metal Research, Chinese Academy of Sciences, Shenyang 110016, China

${ }^{2}$ School of Materials Science and Engineering, University of Science and Technology of China, Shenyang 110016, China

* Corresponding author (email: fli@imr.ac.cn)
} 
current density and capacity. In addition, Li dendrites can form beyond the pores and volume expansion can take place (Fig. 1a). Moreover, the stress produced on the substrate during Li deposition cannot be released effectively, which damages the integrity of current collectors.

To solve these issues, in this work, we prepared reduced graphene oxide-graphitic carbon nitride $\left(\mathrm{rGO}-\mathrm{C}_{3} \mathrm{~N}_{4}\right.$, denoted as GCN) with highly elastic wrinkled structure as a 3D current collector. We constructed this structure based on our earlier report [27]. Dicyandiamide (DICY) was polymerized into $\mathrm{C}_{3} \mathrm{~N}_{4}$ on the graphene layer. In this case, the wrinkles were formed in the material at micron level during the calcining process as the thermal expansion coefficients of $\mathrm{C}_{3} \mathrm{~N}_{4}$ and graphene were different. At the same time, according to the tip-charge concentration dendrite formation model [28], Li was mainly deposited in the convex part of the wrinkles. The wrinkles were stretched apart because the stress was generated by $\mathrm{Li}$ deposition on the substrate. Therefore, GCN provided more space for volume expansion in Li-metal anodes during cycling (Fig. 1b). In this way, the elastic material released the stress, maintained the structural integrity of the electrode, and improved the electrochemical performance of Li-metal anodes [29]. Lithiophilic $\mathrm{C}_{3} \mathrm{~N}_{4}$ effectively reduced the nucleation overpotential and ensured uniform Li deposition [30-32]. As demonstrated in this study, Li-metal anodes with GCN exhibited small volume expansion, high CE ( $>98.6 \%$ over 300 cycles), and long cycling life of more than $1700 \mathrm{~h}$.

\section{EXPERIMENTAL SECTION}

\section{Materials and synthesis}

GCN was synthesized according to the previously report [27]. Briefly, DICY solution $\left(40 \mathrm{mg} \mathrm{m}^{-1}\right)$ was added to a $\mathrm{GO}$ dispersion at a mass ratio of 3:5 and the mixture was ultrasonically dispersed for $30 \mathrm{~min}$ and then freeze-dried to obtain a GO/DICY aerogel. Finally, the GO/DICY aerogel was heated at $550^{\circ} \mathrm{C}$ for $1-4 \mathrm{~h}$ in $\mathrm{Ar}$ atmosphere to reduce $\mathrm{GO}$ and produce $\mathrm{C}_{3} \mathrm{~N}_{4}$.

\section{Characterizations}

The morphologies and thicknesses of the rGO and GCN electrodes were investigated by scanning electron microscopy (SEM, FEI Nova Nano-SEM 460) and transmission electron microscopy (TEM, Titan Cubed G2, $300 \mathrm{kV}$ ). X-ray diffraction (XRD, Brucker D2 Advance diffractometer) was conducted in the diffraction angle

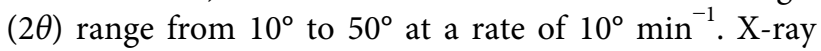
photoelectron spectroscopy (XPS) measurements were carried out on ESCALAB 250 instrument with Al Ka radiation. Data acquisition and processing were carried out on the CASA XPS software. Attenuated total reflectance Fourier-transform infrared spectroscopy (ATRFTIR, Nicolet iS5 iD7 ATR spectrometer) was used to characterize the functional groups in the samples. $\mathrm{N}_{2}$ adsorption-desorption isotherms were measured at $77 \mathrm{~K}$ using Micromeritics ASAP2020. The specific surface area was calculated by the Brunauer-Emmett-Teller (BET) method. The pore size distribution was determined based on the density functional theory (DFT) method.

\section{Cell fabrication}

GCN with a diameter of $15 \mathrm{~mm}$ was used to fabricate half-cells and symmetrical cells. Li@GCN electrodes were used for symmetric cells after $\mathrm{Li}$ deposition at $5.0 \mathrm{~mA} \mathrm{~h} \mathrm{~cm}{ }^{-2}$ on GCN. Lithium nitrate $\left(\mathrm{LiNO}_{3}, 2 \mathrm{wt} \%\right)$ and lithium bistrifluoro-methanesulfonylimide (LiTFSI, $1.0 \mathrm{~mol} \mathrm{~L}^{-1}$ ) in 1,3-dioxolane (DOL) and 1,2-dimethoxyethane (DME) (volume ratio 1:1, Suzhou Duoduo New Chemical Material Co., Ltd.) were used in symmetrical cells. Polyethylene (PE, $19 \mathrm{~mm}$ diameter) was used as the

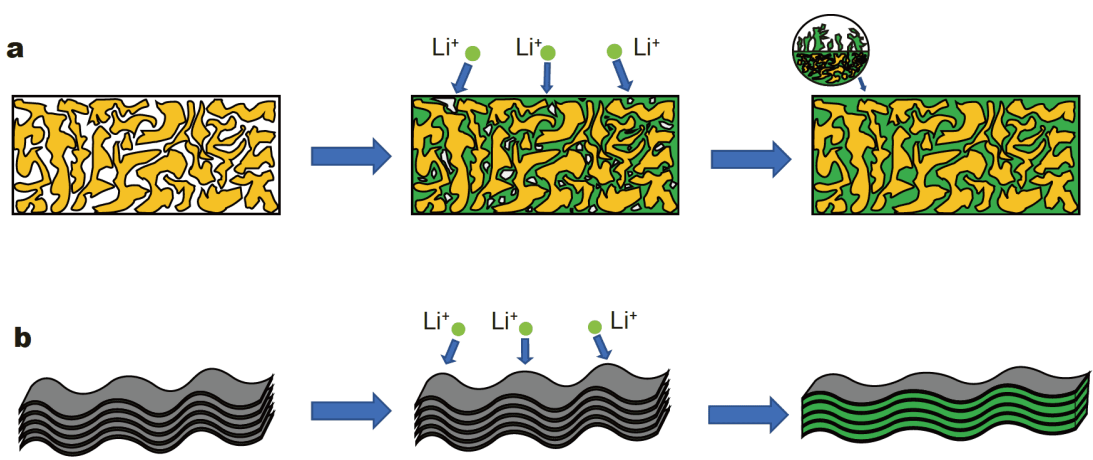

Figure 1 Schematic illustration of Li-metal deposition on different substrates. (a) Inelastic 3D structure and (b) elastic lithiophilic wrinkled structure. 
separator. To fabricate $\mathrm{LiFePO}_{4}$ (LFP) cathodes for full cell testing, LFP powders were mixed with super $\mathrm{P}$ and polyvinylidene fluoride (PVDF) at a weight ratio of 8:1:1. $\mathrm{N}$-methyl-2-pyrrolidone (NMP) was used as the solvent to form slurry. An aluminum foil coated with the slurry was dried at $120^{\circ} \mathrm{C}$ in vacuum overnight and cut into discs of $10 \mathrm{~mm}$ diameter. The final areal mass loading of LFP was $\sim 2.0-2.5 \mathrm{mg} \mathrm{cm}^{-2}$. The capacity ratio of the anode and cathode active materials was kept at 3 . The full cells were tested in the cut-off voltage range of $2.8-4.0 \mathrm{~V}$ at $25^{\circ} \mathrm{C}$. Specific capacities were calculated based on the mass of LFP. Lithium hexafluorophosphate $\left(\mathrm{LiPF}_{6}\right)$ in ethylene carbonate (EC)/diethyl carbonate (DEC)/dimethyl carbonate (DMC) $\left(1.0 \mathrm{~mol} \mathrm{~L}^{-1} ; v: v: v=1: 1: 1\right)$ (Suzhou Duoduo New Chemical Material Co., Ltd.) was used as the electrolyte in Li |LFP cells. The separator used was the same as the half cells and symmetrical cells. CE of half cells was tested in both ester and ether electrolyte systems. The amount of electrolyte used in all cells was $60 \mu \mathrm{L}$.

\section{Electrochemical measurements}

Electrochemical impedance spectroscopy (EIS) was conducted to evaluate the electrochemical performance of the electrodes on a VSP-300 multichannel workstation. Testing was carried out in the frequency range from $10 \mathrm{mHz}$ to $100 \mathrm{kHz}$ at a perturbation amplitude of $5 \mathrm{mV}$ $v s$. the open-circuit potential.

\section{RESULTS AND DISCUSSION}

The XRD patterns of $\mathrm{C}_{3} \mathrm{~N}_{4}, \mathrm{rGO}$, and GCN are shown in
Fig. 2a. $\mathrm{C}_{3} \mathrm{~N}_{4}$ exhibited obvious characteristic peaks at $13.1^{\circ}$ and $27.4^{\circ}$, representing the (100) and (002) planes, respectively. The peak located at $26^{\circ}$ was assigned to the (002) plane of rGO [33]. The pattern of GCN showed one characteristic peak of $\mathrm{C}_{3} \mathrm{~N}_{4}$ at $13.1^{\circ}$ and one composite peak at $26.7^{\circ}$. Meanwhile, the FTIR spectrum of GCN contained unique breathing vibration peak corresponding to tri-s-triazine units $(\mathrm{C}-\mathrm{N}=\mathrm{C})$ at $810 \mathrm{~cm}^{-1}$ (Fig. S1). The XRD and FTIR results of GCN indicated the existence of $\mathrm{C}_{3} \mathrm{~N}_{4}$ on rGO. The TEM image in Fig. $2 \mathrm{~b}$ shows that GCN was composed of uniformly distributed $\mathrm{C}_{3} \mathrm{~N}_{4}$ nanocrystals with (200) interplanar spacing of $\sim 0.37 \mathrm{~nm}$ from the diffraction pattern. This illustrated that DICY was polymerized into $\mathrm{C}_{3} \mathrm{~N}_{4}$ on $\mathrm{rGO}$ [34]. According to the $\mathrm{N}_{2}$ adsorption-desorption isotherms and pore size distribution (Fig. S2), the pore structure of GCN contained micropores, mesopores and macropores with a pore volume of $0.044 \mathrm{~cm}^{3} \mathrm{~g}^{-1}$ and specific surface area of $14.44 \mathrm{~m}^{2} \mathrm{~g}^{-1}$.

The morphological differences between rGO and GCN were further characterized by SEM (Fig. $2 \mathrm{c}$ and d). While the surface of rGO was flat and smooth (Fig. 2c), GCN exhibited homogeneous wrinkled structure (Fig. $2 \mathrm{~d}$ and Fig. S3). To verify that this wrinkled structure has high elasticity and good resilience, cyclic mechanical tests were conducted (Fig. 2e). The area of the hysteresis loop over 100 cycles was small, indicating that energy loss during the loading-unloading process was negligible and the material underwent elastic deformation. After cycling, there was no large deviation in the strain and the overlap between the curves was relatively high, indicating good resilience in the material [35-37]. As shown in the SEM
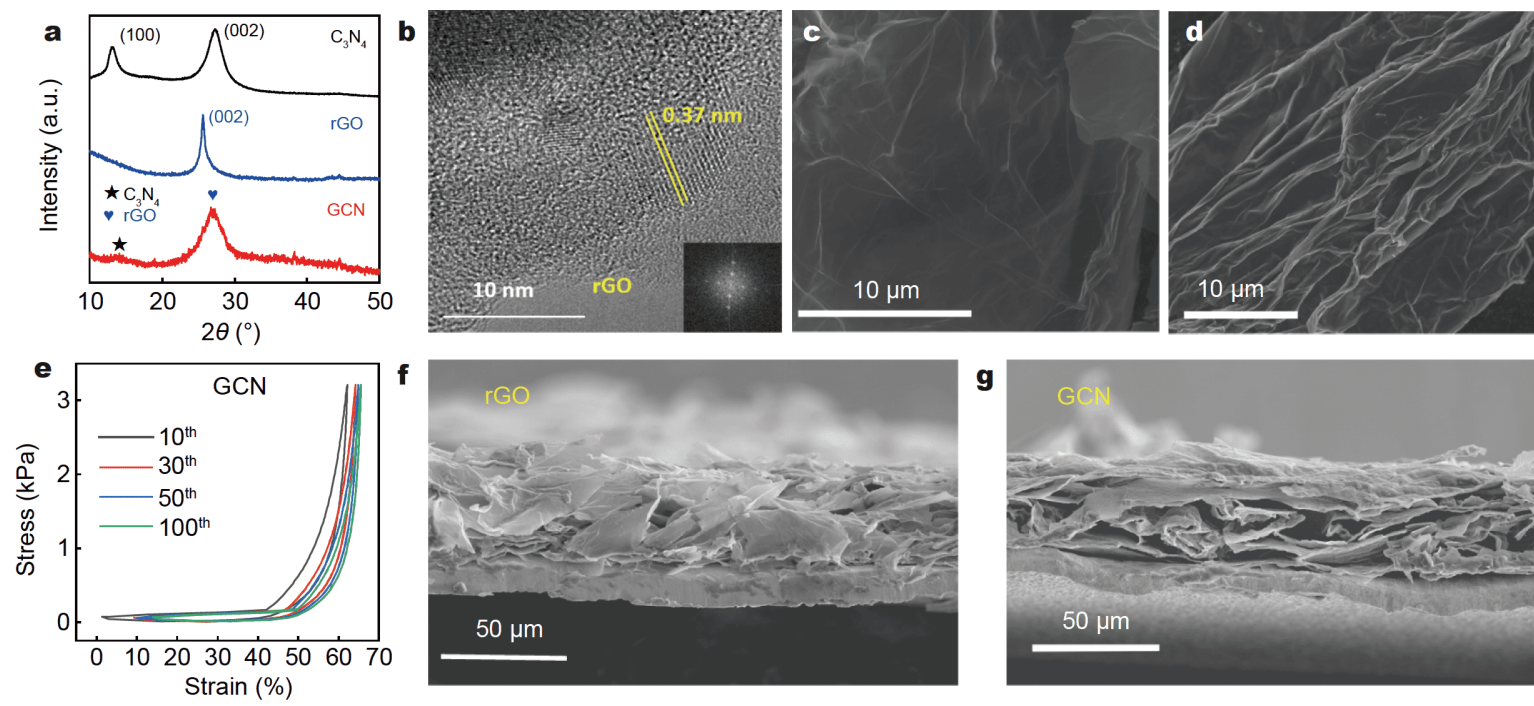

Figure 2 (a) XRD patterns of $\mathrm{C}_{3} \mathrm{~N}_{4}$, rGO, and GCN. (b) TEM image of GCN. SEM images of rGO (c) and GCN (d), repectively. (e) Stress-strain curves of GCN over 100 cycles. (f) rGO and (g) GCN electrode structures after charge-discharge cycling. 
images, there were no wrinkles on the rGO surface, and it was not elastic. Therefore, the rGO electrode was unable to support the stress caused by volume expansion during Li plating/stripping and can suffer from the structural failure (Fig. 2f). In contrast, GCN could release the stress effectively and maintain structural integrity after cycling (Fig. 2g).

Electrode thicknesses after charge-discharge cycling were measured by SEM to understand the vital role played by the highly elastic wrinkled structure in restricting volume expansion in the electrode. The initial thickness of the rGO electrode was $61.92 \mu \mathrm{m}$ (Fig. 3a). After 300 cycles at $1.0 \mathrm{~mA} \mathrm{~cm}^{-2}$ and 100 cycles at $5.0 \mathrm{~mA} \mathrm{~cm}{ }^{-2}$, the electrode produced a large amount of non-active $\mathrm{Li}$. Under these conditions, the expansion rates of the rGO electrode were $409.2 \%$ (Fig. 3b) and $386.8 \%$ (Fig. 3c), respectively, compared with the initial thicknesses. These results show that the rGO electrode experienced severe expansion. Meanwhile, the initial thickness of GCN was $71.76 \mu \mathrm{m}$ (Fig. 3d), and it ex- panded by only $93.1 \%$ (Fig. 3e) and $142.8 \%$ (Fig. 3f) after 300 cycles at $1.0 \mathrm{~mA} \mathrm{~cm}^{-2}$ and 100 cycles at $5.0 \mathrm{~mA} \mathrm{~cm}^{-2}$, respectively. It should be noticed that the strain could not be completely released after long cycles $[38,39]$, and the recoverability of the GCN electrode got worse in the stripping process. This would cause a more obvious volume expansion of the GCN electrode after 300 chargedischarge cycles. However, it can still be categorically stated that the expansion rates of the GCN electrode were lower than those of the rGO electrode under different charge-discharge cycling conditions. Furthermore, the advantages became more obvious with the current density and charge-discharge cycles (Fig. 3g). These results indicate that the highly elastic and resilient structure of GCN played significant role in reducing electrode volume expansion. Furthermore, it was found that $\mathrm{Li}$ was deposited between the pores in the structure of rGO, which slightly increased the thickness of the electrode to $66.88 \mu \mathrm{m}$ after Li deposition at $1.0 \mathrm{~mA} \mathrm{~h} \mathrm{~cm}^{-2}$. In the case of the GCN electrode, Li was uniformly deposited owing
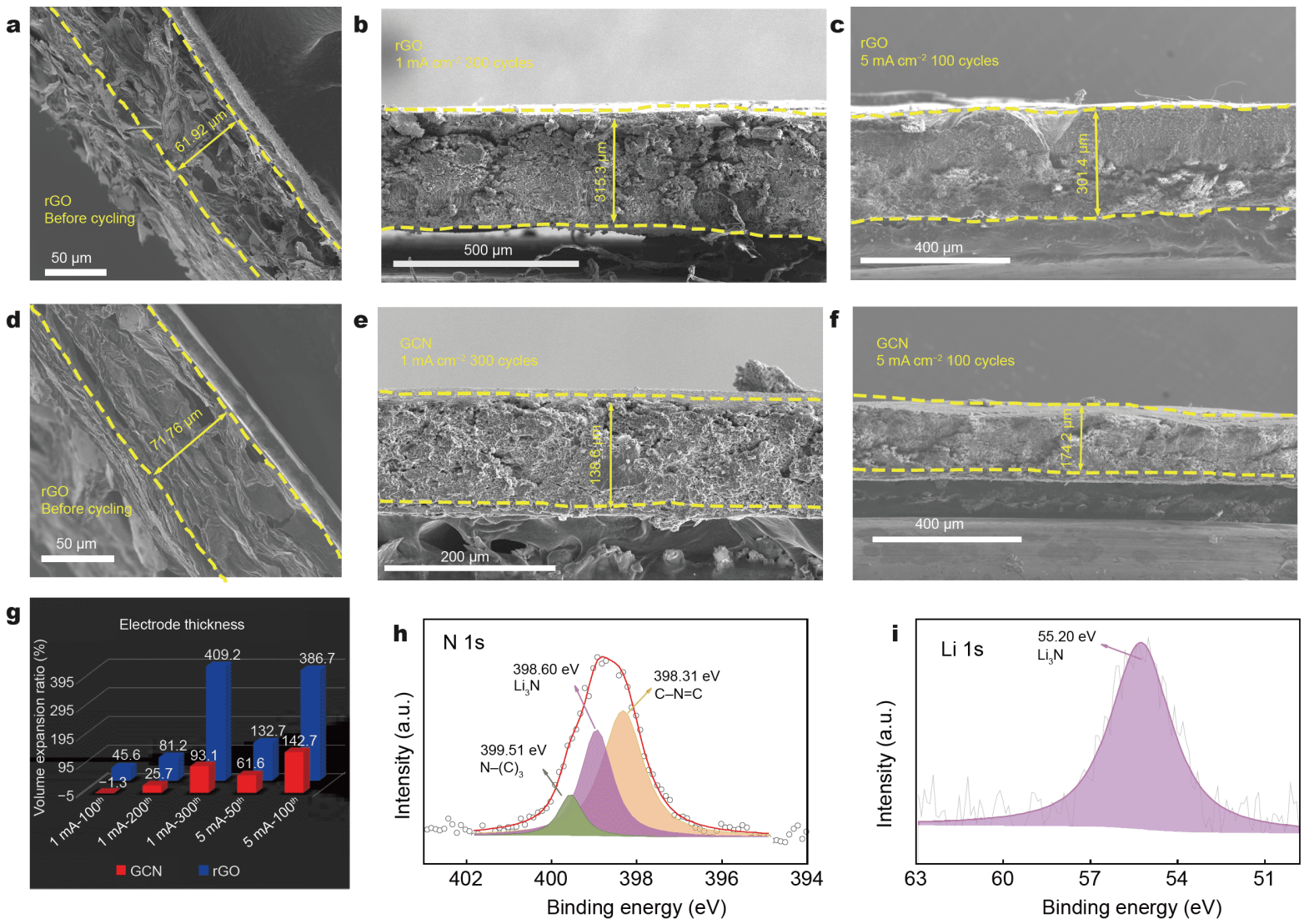

Figure 3 (a, d) Initial thicknesses of the rGO and GCN electrodes. (b, e) Thicknesses of the rGO and GCN electrodes after 300 cycles at $1.0 \mathrm{~mA} \mathrm{~cm}^{-2}$. (c, f) Thicknesses of the rGO and GCN electrodes after 100 cycles at $5 \mathrm{~mA} \mathrm{~cm}^{-2}$. (g) Comparison of electrode thickness-expansion rate corresponding to different current densities and number of cycles. (h, i) XPS spectra of N 1s and Li 1s of GCN after lithiation. 
to lithiophilicity of $\mathrm{C}_{3} \mathrm{~N}_{4}$. The wrinkled structure stretched apart under stress, resulting in the thickness of $49.29 \mu \mathrm{m}$ (Fig. S4), which was smaller than the original thickness. To further investigate the reaction between $\mathrm{Li}$ and $\mathrm{C}_{3} \mathrm{~N}_{4}$ and verify the lithiophilicity of $\mathrm{C}_{3} \mathrm{~N}_{4}$, XPS was conducted to study the chemical compositions of the GCN and Li@GCN electrodes. The N 1s spectrum (Fig. S5) of GCN before lithiation exhibited a strong peak at $398.03 \mathrm{eV}$, which could be attributed to the $\mathrm{sp}^{2}$ hybridization of $\mathrm{N}$ atoms and the combination of $\mathrm{C}$ atoms in $\mathrm{C}-\mathrm{N}=\mathrm{C}$ groups. In addition, two peaks could be observed at 399.20 and $400.70 \mathrm{eV}$, corresponding to $\mathrm{N}-(\mathrm{C})_{3}$ and $\mathrm{C}-\mathrm{NH}_{2}$, respectively. The $\mathrm{N}$ 1s pattern of GCN after lithiation is shown in Fig. $3 \mathrm{~h}$. In this case, in addition to the peaks of $\mathrm{C}-\mathrm{N}=\mathrm{C}$ and $\mathrm{N}-(\mathrm{C})_{3}$ at 398.31 and $399.51 \mathrm{eV}$, respectively, a new peak corresponding to $\mathrm{Li}_{3} \mathrm{~N}$ at $398.60 \mathrm{eV}$ was observed. Meanwhile, Li 1s spectroscopy (Fig. 3i) also indicated an $\mathrm{Li}_{3} \mathrm{~N}$ peak at $55.20 \mathrm{eV}$ [30], suggesting that $\mathrm{Li}$ reacted with $\mathrm{C}_{3} \mathrm{~N}_{4}$ to form $\mathrm{Li}_{3} \mathrm{~N}$.

A comparison of the nucleation overpotentials of different electrodes further proved the lithiophilicity of $\mathrm{C}_{3} \mathrm{~N}_{4}$. The nucleation overpotential of GCN was $15 \mathrm{mV}$ at $1 \mathrm{~mA} \mathrm{~cm}{ }^{-2}$, which was much lower than that of the rGO $(25 \mathrm{mV})$ and $\mathrm{Cu}(58 \mathrm{mV})$ electrodes (Fig. 4a). In addition, the nucleation overpotential of GCN was the lowest among the tested electrodes at different current densities. Even at a current density as high as $5.0 \mathrm{~mA} \mathrm{~cm}^{-2}$, it exhibited a low overpotential of $66 \mathrm{mV}$ (Fig. 4b). This suggests that the excellent lithiophilicity of $\mathrm{C}_{3} \mathrm{~N}_{4}$ helped in effectively reducing the Li nucleation barrier (Table S1) and facilitated the uniform deposition of Li. Subsequently, half-cells were assembled and the Li plating/ stripping performances of different electrodes were evaluated. The CE of the GCN electrode was $98.6 \%$ at $1.0 \mathrm{~mA} \mathrm{~cm}^{-2}$ and $1.0 \mathrm{~mA} \mathrm{~h} \mathrm{~cm}^{-2}$ over 300 cycles in ether electrolyte. Under the same conditions, the CEs of the $\mathrm{rGO}$ and $\mathrm{Cu}$ electrodes began to decay at the $180^{\text {th }}$ and $50^{\text {th }}$ cycles with values of $96.6 \%$ and $95.0 \%$, respectively (Fig. 4c). At the same capacity and different current densities, compared with other Li-metal batteries with 3D graphene current collectors, GCN exhibited advantages in terms of CE and cycling life (Fig. 4d and Table S2) [4051]. At $5.0 \mathrm{~mA} \mathrm{~cm}^{-2}$ in ether electrolyte, the GCN electrode remained stable even after 100 cycles, while the rGO electrode exhibited fluctuating performance after 40 cycles. This can be attributed to severe dendrite growth and partial short-circuit due to uneven Li-ion flux on the rGO electrode. Meanwhile, the $\mathrm{Cu}$ electrode could not cycle at such high current density and short-circuited early in the test (Fig. S6). Furthermore, the CE of the
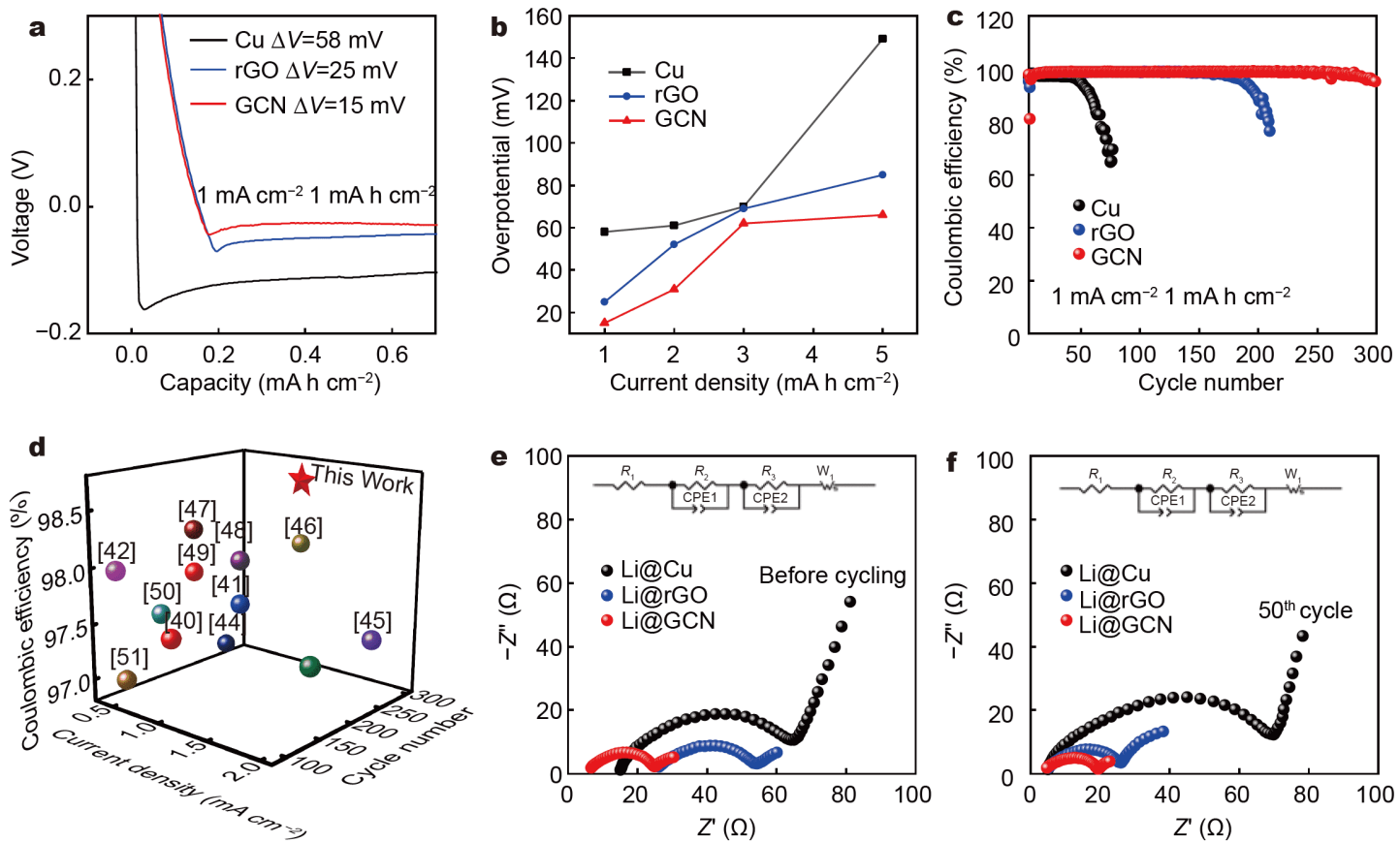

Figure 4 (a) Overpotentials of the $\mathrm{Cu}, \mathrm{rGO}$, and $\mathrm{GCN}$ electrodes with $1.0 \mathrm{~mA} \mathrm{~h} \mathrm{~cm}^{-2}$ at $1.0 \mathrm{~mA} \mathrm{~cm}^{-2}$. (b) Current densities in the range of $1.0-5.0 \mathrm{~mA} \mathrm{~cm}^{-2}$. (c) CEs of the $\mathrm{Cu}, \mathrm{rGO}$, and GCN electrodes with $1.0 \mathrm{~mA} \mathrm{~h} \mathrm{~cm}{ }^{-2}$ at $1.0 \mathrm{~mA} \mathrm{~cm}{ }^{-2}$. (d) Electrochemical performance of Li-metal batteries with 3D graphene current collectors. (e, f) EIS curves for of the Li@Cu, Li@rGO, and Li@GCN symmetrical cells before cycling and after 50 cycles. 
GCN electrode in ester electrolyte was shown in Fig. S7, it was $80.0 \%$ at $1.0 \mathrm{~mA} \mathrm{~cm}^{-2}$ and $1.0 \mathrm{~mA} \mathrm{~h} \mathrm{~cm}^{-2}$ over 80 cycles and began to decay at the $40^{\text {th }}$ cycles with a value of $78.0 \%$ at $5.0 \mathrm{~mA} \mathrm{~cm}^{-2}$. These observations indicate that the GCN electrode containing lithiophilic $\mathrm{C}_{3} \mathrm{~N}_{4}$ exhibited stable structure with little expansion. In addition, it exhibited good reversibility, as well as high $\mathrm{CE}$ and long cycle life during Li plating/stripping at high current density and capacity.

EIS analysis showed that the GCN electrode exhibited an SEI resistance $\left(R_{\mathrm{SEI}}\right)$ of $9.7 \Omega$ and charge transfer resistance $\left(R_{\mathrm{ct}}\right)$ of $9.2 \Omega$ before cycling (Fig. $4 \mathrm{e}$ ). After 50 cycles, the $R_{\mathrm{SEI}}$ and $R_{\mathrm{ct}}$ values were 9.2 and $6.0 \Omega$, respectively, which were smaller than those of the rGO and $\mathrm{Cu}$ electrodes cycled under the same conditions (Fig. 4f). After 100 cycles, the $R_{\mathrm{SEI}}$ and $R_{\mathrm{ct}}$ of the GCN electrode were 7.9 and $4.0 \Omega$, respectively (Fig. S8), suggesting a small interface resistance and rapid charge transfer process. As discussed earlier, serious volume expansion occurred in the $\mathrm{Cu}$ and $\mathrm{rGO}$ electrodes, resulting in continuous fracture and regeneration of the SEI films. This also led to unstable $R_{\mathrm{SEI}}$ and increasing in $R_{\mathrm{ct}}$. In contrast, stable SEI was formed on the surface of the GCN electrode, which resulted in decreasing $R_{\mathrm{SEI}}$ and $R_{\mathrm{ct}}$. In turn, it indicated rapid charge transfer (Table S3).

Symmetrical cells were fabricated to test the long-cycling stability of the electrodes. As shown in Fig. 5a, the Li@GCN electrode was stable for over $1700 \mathrm{~h}$ at $1.0 \mathrm{~mA} \mathrm{~cm}^{-2}$. It exhibited stable performance for a much longer period than the Li@rGO and Li@Cu electrodes. When the current density was raised to 2 and $3.0 \mathrm{~mA} \mathrm{~cm}^{-2}$, the Li@GCN electrode exhibited a stable cycling performance to 1100 and $550 \mathrm{~h}$, respectively (Fig. S9). The rate performance of the symmetrical cells in Fig. 5b shows that the Li@GCN electrode exhibited low polarization at different current densities. Its voltage hysteresis was less than $40 \mathrm{mV}$ even at a current density as high as $6.0 \mathrm{~mA} \mathrm{~cm}^{-2}$, indicating that Li@GCN showed excellent $\mathrm{Li}$ plating/stripping kinetics. A full cell with Li@GCN anode and LFP cathode was assembled to further study the role of GCN. As shown in Fig. $5 c$, the capacities of the Li@GCN||LFP cell were 138.5, 138.3, 135.3 , and $130 \mathrm{~mA} \mathrm{~h} \mathrm{~g}^{-1}$ at $0.2,0.5,1$, and $2 \mathrm{C}(1 \mathrm{C}=$ $170 \mathrm{~mA} \mathrm{~g}^{-1}$ ), respectively, and were higher than those of the Li@rGO||LFP and Li@Cu||LFP cells. When the rate was back to $0.2 \mathrm{C}$, the capacity recovered to $137 \mathrm{~mA} \mathrm{~h} \mathrm{~g}^{-1}$ (99.2\% retention). Fig. 5d compares the long cycling capabilities at 1 C. After 60 cycles, the capacity of Li@Cull LFP was completely decayed, while Li@rGO||LFP and Li@GCN||LFP exhibited capacity retentions of 85.01\% and $98.15 \%$, respectively. Even after 100 cycles, the capacity retention and CE of Li@GCN||LFP were 89.46\% and $98.67 \%$, respectively. From the voltage profiles of Li@Cu||LFP and Li@GCN||LFP (Fig. 5e and f), it can be inferred that the capacity of Li@Cu||LFP decayed rapidly and the overpotential increased. As for Li@GCN||LFP, there were minimal changes in its capacity and overpotential after 100 cycles. These observations once again
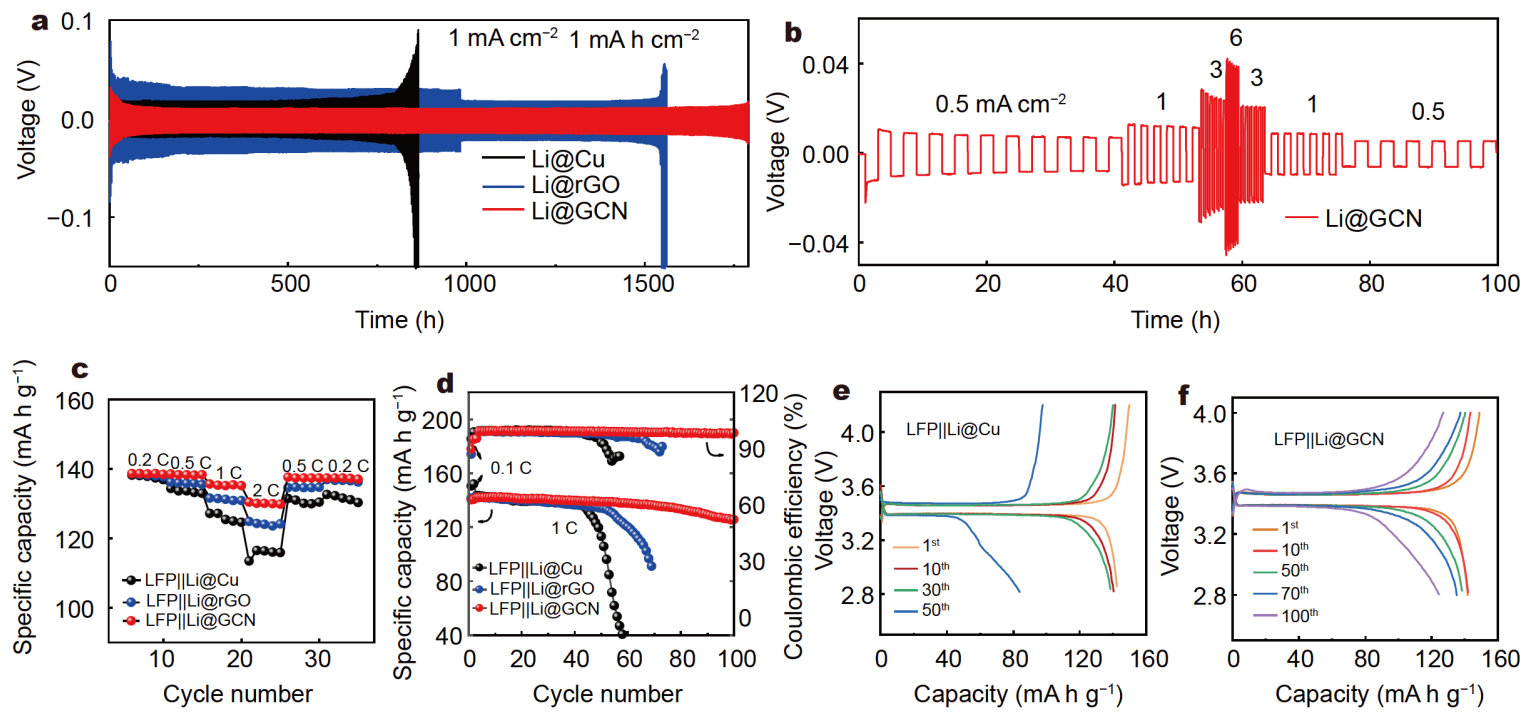

Figure 5 (a) Voltage profiles of symmetrical cells with the Li@Cu, Li@rGO, and Li@GCN electrodes at $1.0 \mathrm{~mA} \mathrm{~cm}^{-2}$. (b) Rate performance of the symmetrical cell with the Li@GCN electrode at current densities of 0.5-6.0 mA cm ${ }^{-2}$. (c) Rate performance of full cells with the Li@Cu, Li@rGO, and Li@GCN electrodes from 0.2 to 2 C. (d) Cycling performance of full cells with the Li@Cu, Li@rGO, and Li@GCN electrodes at 1 C. (e, f) Voltage profiles of the Li@Cu||LFP and Li@GCN||LFP cells at 1C. 
indicate that the highly elastic $3 \mathrm{D}$ current collector we developed can effectively stabilize Li-metal anodes and improve the stability of Li-metal batteries.

\section{CONCLUSIONS}

A 3D current collector with highly elastic, lithiophilic sites, and wrinkled structure was developed in this study for Li-metal anodes. This highly elastic structure effectively released the stress caused by Li deposition on the substrate, thus ensuring the integrity of the structure and limiting its volume expansion. Because $\mathrm{C}_{3} \mathrm{~N}_{4}$ was lithiophilic, it reduced the nucleation overpotential and led to uniform deposition of Li. Li-metal anodes with GCN as the current collector exhibited high CE of $98.6 \%$ after 300 cycles and long cycle life of more than $1700 \mathrm{~h}$ at $1.0 \mathrm{~mA} \mathrm{~cm}^{-2}$. Meanwhile, the capacity-retention rate of the cells assembled with LFP was $98.15 \%$ after 100 cycles at $1 \mathrm{C}$. The insights gained from this study offer a simple and practical method to effectively enhance the performance of Li-metal batteries and suggest a new approach for 3D current collector development.

Received 3 February 2021; accepted 23 March 2021; published online 8 June 2021

1 Lu Y, Zhang Q, Chen J. Recent progress on lithium-ion batteries with high electrochemical performance. Sci China Chem, 2019, 62: 533-548

2 Park S, Jin HJ, Yun YS. Advances in the design of 3D-structured electrode materials for lithium-metal anodes. Adv Mater, 2020, 32: 2002193

3 Lin D, Liu Y, Cui Y. Reviving the lithium metal anode for highenergy batteries. Nat Nanotech, 2017, 12: 194-206

4 Duan J, Zheng Y, Luo W, et al. Is graphite lithiophobic or lithiophilic? Natl Sci Rev, 2020, 7: 1208-1217

5 Nanda S, Gupta A, Manthiram A. Anode-free full cells: A pathway to high-energy density lithium-metal batteries. Adv Energy Mater, 2021, 11: 2000804

6 Li L, Li S, Lu Y. Suppression of dendritic lithium growth in lithium metal-based batteries. Chem Commun, 2018, 54: 6648-6661

7 Liu S, Xia X, Deng S, et al. Large-scale synthesis of high-quality lithium-graphite hybrid anodes for mass-controllable and cyclingstable lithium metal batteries. Energy Storage Mater, 2018, 15: 3136

8 He D, Liao Y, Cheng Z, et al. Facile one-step vulcanization of copper foil towards stable Li metal anode. Sci China Mater, 2020, 63: 1663-1671

9 Zhang L, Yang T, Du C, et al. Lithium whisker growth and stress generation in an in situ atomic force microscope-environmental transmission electron microscope set-up. Nat Nanotechnol, 2020, 15: 94-98

10 Yu SH, Huang X, Brock JD, et al. Regulating key variables and visualizing lithium dendrite growth: An Operando X-ray study. J Am Chem Soc, 2019, 141: 8441-8449

11 Guo Y, Li H, Zhai T. Reviving lithium-metal anodes for nextgeneration high-energy batteries. Adv Mater, 2017, 29: 1700007
12 Wu S, Zhang Z, Lan M, et al. Lithiophilic Cu-CuO-Ni hybrid structure: Advanced current collectors toward stable lithium metal anodes. Adv Mater, 2018, 30: 1705830

13 Chen Y, Ke X, Cheng Y, et al. Boosting the electrochemical performance of 3D composite lithium metal anodes through synergistic structure and interface engineering. Energy Storage Mater, 2020, 26: 56-64

14 Wu H, Zhang Y, Deng Y, et al. A lightweight carbon nanofiberbased 3D structured matrix with high nitrogen-doping level for lithium metal anodes. Sci China Mater, 2019, 62: 87-94

$15 \mathrm{Wu} \mathrm{W}$, Duan J, Wen J, et al. A writable lithium metal ink. Sci China Chem, 2020, 63: 1483-1489

16 Shen Z, Zhang W, Li S, et al. Tuning the interfacial electronic conductivity by artificial electron tunneling barriers for practical lithium metal batteries. Nano Lett, 2020, 20: 6606-6613

17 Chen J, Zhao J, Lei L, et al. Dynamic intelligent $\mathrm{Cu}$ current collectors for ultrastable lithium metal anodes. Nano Lett, 2020, 20: 3403-3410

18 Luo Y, Li T, Zhang $\mathrm{H}$, et al. New insights into the formation of silicon-oxygen layer on lithium metal anode via in situ reaction with tetraethoxysilane. J Energy Chem, 2021, 56: 14-22

19 Han Y, Zhou Y, Zhu J, et al. Dual effects from in-situ polymerized gel electrolyte and boric acid for ultra-long cycle-life Li metal batteries. Sci China Mater, 2020, 63: 2344-2350

20 Guan X, Wang A, Liu S, et al. Controlling nucleation in lithium metal anodes. Small, 2018, 14: 1801423

21 Biswal P, Stalin S, Kludze A, et al. Nucleation and early stage growth of Li electrodeposits. Nano Lett, 2019, 19: 8191-8200

$22 \mathrm{Wu} \mathrm{K}$, Zhao B, Yang $\mathrm{C}$, et al. $\mathrm{ZnCo}_{2} \mathrm{O}_{4} / \mathrm{ZnO}$ induced lithium deposition in multi-scaled carbon/nickel frameworks for dendritefree lithium metal anode. J Energy Chem, 2020, 43: 16-23

23 Lin D, Liu Y, Liang Z, et al. Layered reduced graphene oxide with nanoscale interlayer gaps as a stable host for lithium metal anodes. Nat Nanotech, 2016, 11: 626-632

24 Zhou Y, Zhang X, Ding Y, et al. Redistributing Li-ion flux by parallelly aligned holey nanosheets for dendrite-free Li metal anodes. Adv Mater, 2020, 32: 2003920

25 Ye H, Zheng ZJ, Yao HR, et al. Guiding uniform Li plating/ stripping through lithium-aluminum alloying medium for long-life Li metal batteries. Angew Chem Int Ed, 2019, 58: 1094-1099

26 Chen X, Chen XR, Hou TZ, et al. Lithiophilicity chemistry of heteroatom-doped carbon to guide uniform lithium nucleation in lithium metal anodes. Sci Adv, 2019, 5: eaau7728

27 Chen J, Wen L, Liang J, et al. Tunable in situ stress and spontaneous microwrinkling of multiscale heterostructures. J Phys Chem C, 2019, 123: 26041-26046

28 Ding F, Xu W, Graff GL, et al. Dendrite-free lithium deposition via self-healing electrostatic shield mechanism. J Am Chem Soc, 2013, 135: 4450-4456

29 Wang X, Zeng W, Hong L, et al. Stress-driven lithium dendrite growth mechanism and dendrite mitigation by electroplating on soft substrates. Nat Energy, 2018, 3: 227-235

30 Huang $\mathrm{Y}$, Chen B, Duan J, et al. Graphitic carbon nitride $\left(\mathrm{g}-\mathrm{C}_{3} \mathrm{~N}_{4}\right)$ : An interface enabler for solid-state lithium metal batteries. Angew Chem Int Ed, 2020, 59: 3699-3704

31 Ye S, Wang L, Liu F, et al. $\mathrm{g}-\mathrm{C}_{3} \mathrm{~N}_{4}$ derivative artificial organic/ inorganic composite solid electrolyte interphase layer for stable lithium metal anode. Adv Energy Mater, 2020, 10: 2002647

32 Lu Z, Liang Q, Wang B, et al. Graphitic carbon nitride induced micro-electric field for dendrite-free lithium metal anodes. Adv 
Energy Mater, 2019, 9: 1803186

33 Kessler FK, Zheng Y, Schwarz D, et al. Functional carbon nitride materials-design strategies for electrochemical devices. Nat Rev Mater, 2017, 2: 17030

34 Guo Y, Niu P, Liu Y, et al. An autotransferable g- $\mathrm{C}_{3} \mathrm{~N}_{4} \mathrm{Li}^{+}-$modulating layer toward stable lithium anodes. Adv Mater, 2019, 31: 1900342

$35 \mathrm{Xu}$ X, Zhang Q, Yu Y, et al. Naturally dried graphene aerogels with superelasticity and tunable Poisson's ratio. Adv Mater, 2016, 28: 9223-9230

$36 \mathrm{Wu} \mathrm{Y,} \mathrm{Yi} \mathrm{N,} \mathrm{Huang} \mathrm{L,} \mathrm{et} \mathrm{al.} \mathrm{Three-dimensionally} \mathrm{bonded} \mathrm{spongy}$ graphene material with super compressive elasticity and near-zero Poisson's ratio. Nat Commun, 2015, 6: 6141

$37 \mathrm{Hu} \mathrm{H}$, Zhao Z, Wan W, et al. Ultralight and highly compressible graphene aerogels. Adv Mater, 2013, 25: 2219-2223

38 Zhao Y, Feng J, Liu X, et al. Self-adaptive strain-relaxation optimization for high-energy lithium storage material through crumpling of graphene. Nat Commun, 2014, 5: 4565

39 Deng S, Berry V. Wrinkled, rippled and crumpled graphene: An overview of formation mechanism, electronic properties, and applications. Mater Today, 2016, 19: 197-212

40 Pan L, Luo Z, Zhang Y, et al. Seed-free selective deposition of lithium metal into tough graphene framework for stable lithium metal anode. ACS Appl Mater Interfaces, 2019, 11: 44383-44389

41 Song Q, Yan H, Liu K, et al. Vertically grown edge-rich graphene nanosheets for spatial control of Li nucleation. Adv Energy Mater, 2018, 8: 1800564

42 Zhang R, Chen XR, Chen X, et al. Lithiophilic sites in doped graphene guide uniform lithium nucleation for dendrite-free lithium metal anodes. Angew Chem Int Ed, 2017, 56: 7764-7768

43 Wang H, Li Y, Li Y, et al. Wrinkled graphene cages as hosts for high-capacity Li metal anodes shown by cryogenic electron microscopy. Nano Lett, 2019, 19: 1326-1335

44 Yang G, Chen J, Xiao P, et al. Graphene anchored on $\mathrm{Cu}$ foam as a lithiophilic 3D current collector for a stable and dendrite-free lithium metal anode. J Mater Chem A, 2018, 6: 9899-9905

45 Huang S, Yang H, Hu J, et al. Early lithium plating behavior in confined nanospace of 3D lithiophilic carbon matrix for stable solid-state lithium metal batteries. Small, 2019, 15: 1904216

46 Zhu W, Deng W, Zhao F, et al. Graphene network nested Cu foam for reducing size of lithium metal towards stable metallic lithium anode. Energy Storage Mater, 2019, 21: 107-114

47 Wang T, Zhai P, Legut D, et al. S-doped graphene-regional nucleation mechanism for dendrite-free lithium metal anodes. Adv Energy Mater, 2019, 9: 1804000

48 Li BQ, Chen XR, Chen X, et al. Favorable lithium nucleation on lithiophilic framework porphyrin for dendrite-free lithium metal anodes. Research, 2019, 2019: 1-11

49 Zhang R, Wen S, Wang N, et al. N-doped graphene modified 3D porous $\mathrm{Cu}$ current collector toward microscale homogeneous $\mathrm{Li}$ deposition for Li metal anodes. Adv Energy Mater, 2018, 8: 1800914

50 Wang X, Pan Z, Wu Y, et al. Reducing lithium deposition overpotential with silver nanocrystals anchored on graphene aerogel. Nanoscale, 2018, 10: 16562-16567

51 Nie X, Zhang A, Liu Y, et al. Synthesis of interconnected graphene framework with two-dimensional protective layers for stable lithium metal anodes. Energy Storage Mater, 2019, 17: 341-348

Acknowledgements This work was supported by the National Natural
Science Foundation of China (51525206 and 51927803), the National Key R\&D Program of China (2016YFA0200100 and 2016YFB0100100), the Strategic Priority Research Program of the Chinese Academy of Sciences (XDA22010602), Liaoning Revitalization Talents Program (XLYC1908015), and China Petrochemical Cooperation (218025). The authors thank Mrs. Juan Li and Mr. Bo Wen for their valuable discussion.

Author contributions Lu W prepared and characterized the samples. Chen J performed mechanical tests. Lu W, Yang H, and Sun C analyzed experimental data and prepared the manuscript. Li F supervised the project and revised the manuscript. All authors contributed to the general discussion.

Conflict of interest The authors declare that they have no conflict of interest.

Supplementary information Experimental details and supporting data are available in the online version of the paper.

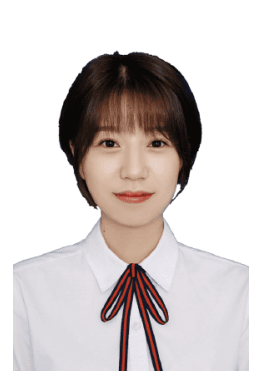

Wenwen Lu is a master's candidate at the Institute of Metal Research, Chinese Academy of Sciences (IMR, CAS). Her research interests include the syntheses and characterizations of 3D current collectors for lithium-metal anodes.

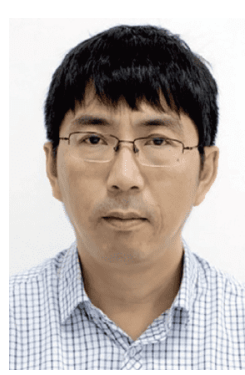

Feng $\mathbf{L} \mathbf{i}$ is a professor of IMR, CAS. He received his $\mathrm{PhD}$ degree in materials science at IMR, CAS in 2001 supervised by Prof. Hui-Ming Cheng. He mainly works on the novel carbon-based and energy materials for lithium-ion batteries, lithium-sulfur batteries, electrochemical capacitors, and new devices. He obtained the award of the National Science Fund for Distinguished Young Scholars by the National Natural Science Foundation of China.

高弹性波浪结构的三维集流体构建稳定的锂金属 负极

芦雯雯 ${ }^{1,2}$, 杨慧聪 ${ }^{1,2}$, 陈静 ${ }^{1}$, 孙驰航 ${ }^{1}$, 李峰 ${ }^{1,2 *}$

摘要 锂金属由于低电化学还原电位和高比容量, 被认为是最具发 展前景的负极材料. 然而, 锂枝晶和体积膨胀等问题严重制约了锂 金属电池的应用发展. 本研究中, 我们制备了高弹性波浪结构的 $\mathrm{rGO}-\mathrm{C}_{3} \mathrm{~N}_{4}(\mathrm{GCN})$ 作为三维集流体. $\mathrm{GCN}$ 的高弹性可有效释放锂沉 积过程产生的应力, 保持电极结构完整, 减小电极体积膨胀. $\mathrm{C}_{3} \mathrm{~N}_{4}$ 的亲锂性可降低锂的形核过电位, 促进锂离子均匀沉积. GCN作为 三维集流体的锂金属负极, 经 300 个循环后, 仍具有较高的库仑效 率, 低的体积膨胀率和更长的循环寿命. 高弹性波浪结构三维集流 体改善了锂金属负极的电化学性能, 为构建柔性三维集流体提供 了新思路. 